Check for updates

Cite this: RSC Adv., 2018, 8, 35594

Received 30th July 2018

Accepted 30th September 2018

DOI: $10.1039 / \mathrm{c} 8 \mathrm{ra06421k}$

rsc.li/rsc-advances

\section{Significantly improved piezoelectric performance of PZT-PMnN ceramics prepared by spark plasma sintering}

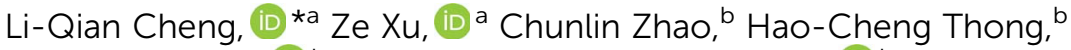 \\ Zhen-Yong Cen, (D) ${ }^{\mathrm{b}}$ Wei Lu, ${ }^{* \mathrm{c}} \mathrm{Yu} \operatorname{Lan}^{\mathrm{c}}$ and Ke Wang (D)
}

A high-performance piezoelectric material, $0.95 \mathrm{~Pb}\left(\mathrm{Zr}_{0.52} \mathrm{Ti}_{0.48}\right) \mathrm{O}_{3}-0.05 \mathrm{~Pb}\left(\mathrm{Mn}_{1 / 3} \mathrm{Nb}_{2 / 3}\right) \mathrm{O}_{3} \quad(\mathrm{PZT}-\mathrm{PMnN})$ ceramic, was prepared by using a spark plasma sintering (SPS) method. By systematically comparing the electrical properties, the spark-plasma-sintered sample was demonstrated to be superior to a conventionally sintered sample. With respect to conventionally sintered ceramic, the $d_{33}$ of sparkplasma-sintered ceramic increases from $323 \mathrm{pC} / \mathrm{N}$ to $412 \mathrm{pC} / \mathrm{N}$, and the $d_{33}^{*}$ increases from $318 \mathrm{pm} \mathrm{V}^{-1}$ to $553 \mathrm{pm} V^{-1}$. More importantly, the mechanical quality factor $\left(Q_{m}\right)$ reaches 583 , which is three times higher than the conventionally sintered sample $\left(Q_{m} \sim 182\right)$. Furthermore, the SPS method was found to be capable of promoting other electrical properties simultaneously. Therefore, the SPS method is proposed to be an effective processing method to fabricate PZT-PMnN ceramics of higher performance.

\section{Introduction}

Piezoelectric ceramic is a kind of functional material which can convert mechanical energy into electrical energy and vice versa. It is widely used in microelectronics, such as in camera focusing systems, fuel injectors, and medical ultrasound. ${ }^{\mathbf{1 - 4}}$ Inside these devices, the piezoelectric actuator is the most important element, and it can provide a very precise and accurate movement under an applied electric field. Therefore, it gains a lot of interest from industry. ${ }^{5}$ As a powerful and cost-effective piezoelectric material, $\mathrm{Pb}(\mathrm{Zr}, \mathrm{Ti}) \mathrm{O}_{3}$ (PZT) and its family have dominated the market of piezoelectric ceramics for a long period.

It is mostly accepted that the criteria for practical applications include an excellent piezoelectric coefficient, good temperature stability, low dielectric loss, and high mechanical quality factor. ${ }^{6-8}$ However, some of these properties are not necessarily required to be outstanding under certain circumstances, e.g. a high mechanical quality factor is more important than a high piezoelectric coefficient in the application of highfrequency ultrasonic transducers. In 1954, Jaffe discovered the $\mathrm{PbZrO}_{3}-\mathrm{PbTiO}_{3}$ system, possessing high piezoelectricity. ${ }^{\mathbf{9}, 10}$ Different elements, acting as a soft or hard doping, when they were doped in PZT ceramics, can improve the ferroelectric properties of ceramics. ${ }^{11}$ On the other hand, Priya et al. analyzed

${ }^{a}$ Department of Materials Science and Engineering, China University of Mining \& Technology (Beijing), Beijing 100083, China. E-mail: chenglq@cumtb.edu.cn

${ }^{b}$ State Key Laboratory of New Ceramics and Fine Processing, School of Materials Science and Engineering, Tsinghua University, Beijing 100084, China

${ }^{c}$ Acoustic Science and Technology Laboratory, Harbin Engineering University, Harbin 150001, China.E-mail: luwei@hrbeu.edu.cn and proved that $\mathrm{Pb}(\mathrm{Zr}$, Ti $) \mathrm{O}_{3}-\mathrm{Pb}\left(\mathrm{Mn}_{1 / 3} \mathrm{Nb}_{2 / 3}\right) \mathrm{O}_{3}$ is suitable for applications, on the basis of the dielectric and piezoelectric magnitudes. ${ }^{12}$

However, PZT ceramics still face many problems, such as the volatilization of lead at the high sintering temperature. ${ }^{13-16}$ Spark plasma sintering (SPS) could be favorable in suppressing the lead loss because of the rapid heating rate, lower sintering temperature and shorter sintering time. ${ }^{17}$ It is well known that SPS is an effective tool to achieve dense and fine-grained ceramics at a relatively low temperature. ${ }^{18}$ For example, Han et al. demonstrated that SPS can reduce the sintering temperature of $\mathrm{Pb}\left(\mathrm{Zr}_{0.52} \mathrm{Ti}_{0.42} \mathrm{Sn}_{0.02} \mathrm{Nb}_{0.04}\right) \mathrm{O}_{3}$ ceramic by about 200$300{ }^{\circ} \mathrm{C}$ while maintaining a high relative density $(>99 \%) .{ }^{19}$ Besides, the SPS method is capable of promoting the performance of piezoceramics. For example, Shen et al. improved the electrical and mechanical properties of $\left(\mathrm{Na}_{0.535} \mathrm{~K}_{0.485}\right)_{1-x} \mathrm{Li}_{x}(-$ $\left.\mathrm{Nb}_{0.8} \mathrm{Ta}_{0.2}\right) \mathrm{O}_{3}(x=0.02-0.07)$ ceramic using SPS method. ${ }^{20}$ This provides a promising alternative to fabricate lead-based ceramics with high mechanical strength and homogeneous fine-grain sizes. ${ }^{21}$ However, there is barely a few papers which systematically investigate and compare the comprehensive electrical properties of spark-plasma-sintered (SPSed) and conventionally sintered (CSed) ceramics.

In this work, $\mathrm{Mn}$ and $\mathrm{Nb}$ co-doped PZT ceramics with the composition 0.95 $\mathrm{Pb}\left(\mathrm{Zr}_{0.52} \mathrm{Ti}_{0.48}\right) \mathrm{O}_{3}-0.05 \mathrm{~Pb}\left(\mathrm{Mn}_{1 / 3} \mathrm{Nb}_{2 / 3}\right) \mathrm{O}_{3}$ (PZT$\mathrm{PMnN}$ ) were prepared by the SPS method at $900-1000{ }^{\circ} \mathrm{C}$. For comparison, the similar composition was prepared by using the conventional sintering (CS) method at $1250{ }^{\circ} \mathrm{C}$. Both ceramic samples were systematically studied. A dense microstructure and high piezoelectric performance are obtained in the SPSed ceramic. This work herein suggests that SPS is an effective 

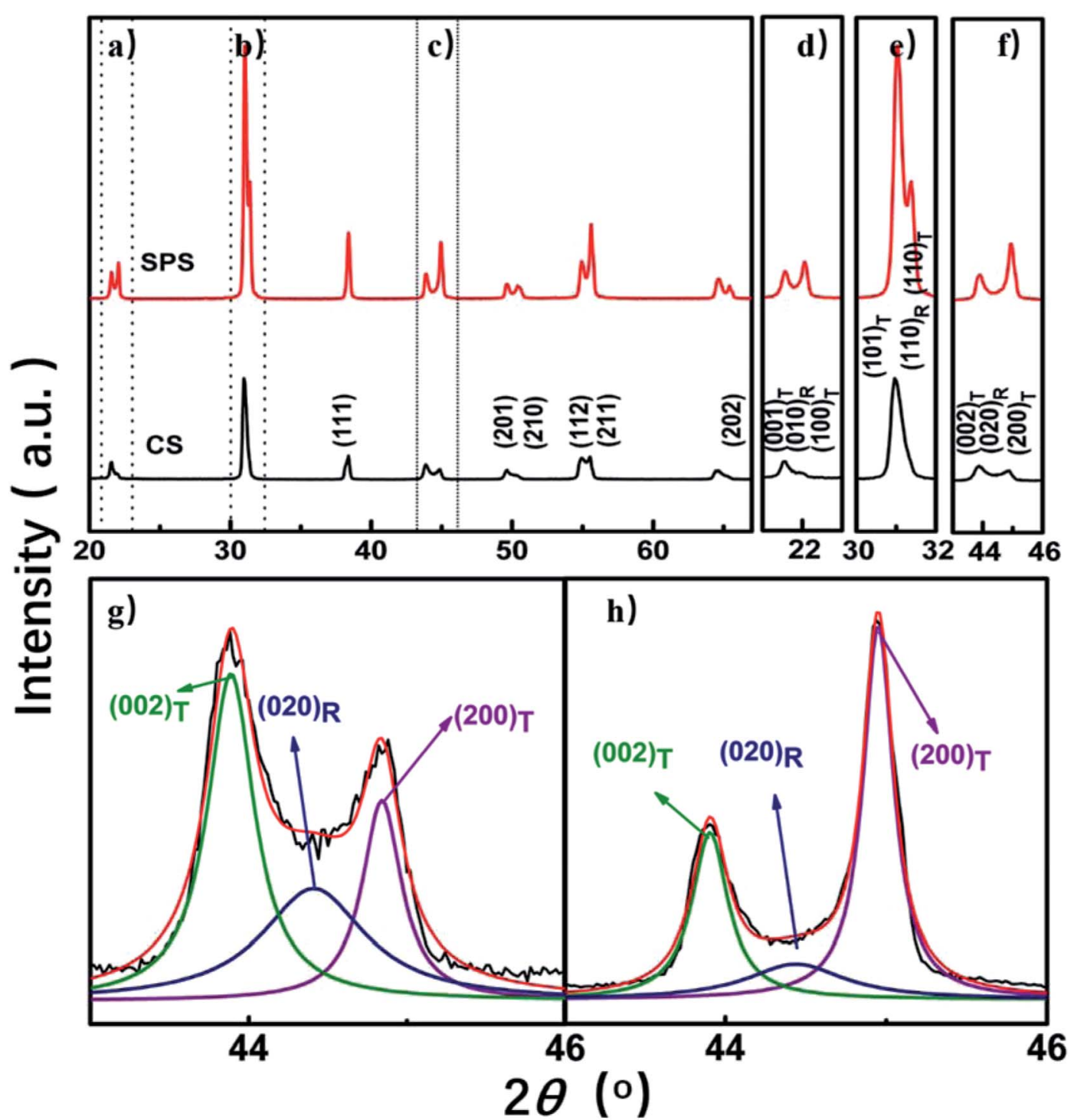

Fig. 1 XRD patterns of PZT-PMnN ceramics prepared by different sintering methods. Peaks at (a), (b) and (c) in the figure are enlarged in (d), (e) and (f), respectively; corresponding XRD patterns at $2 \theta=43-46^{\circ}$ of PZT-PMnN samples sintered by (g) CS, (h) SPS.

method for fabricating high-performance piezoceramics at a low sintering temperature, which is believed to be beneficial for further development of the piezoceramics.

\section{Experimental}

PZT-PMnN piezoceramics were prepared by the SPS and CS method. $\mathrm{Pb}_{3} \mathrm{O}_{4}$ (99\%), $\mathrm{BaCO}_{3}$ (99\%), $\mathrm{TiO}_{2}$ (98\%), $\mathrm{ZrO}_{2}$ (99\%), $\mathrm{Nb}_{2} \mathrm{O}_{5}(99.99 \%)$ and $\mathrm{MnO}_{2}(97.5 \%)$ were weighed according to the stoichiometric formula and mixed together by ball milling in ethanol for 10 hours. The mixture was dried for 2 hours and then calcined for 2 hours at $850^{\circ} \mathrm{C}$. Later, the calcined powder was subjected to the second ball milling process before sintering. The conventional solid-state sintering of PZT-PMnN was performed at $1250{ }^{\circ} \mathrm{C}$ for two hours. For spark plasma sintering, the sintering temperature is generally about $200-300{ }^{\circ} \mathrm{C}$ lower than the conventional solid-state method. Hence, the temperature range of $900-1000{ }^{\circ} \mathrm{C}$ was used in the SPS process. ${ }^{19}$
Approximately $3.5 \mathrm{~g}$ of calcined powder was compacted into a graphite mold with an inner diameter of $10 \mathrm{~mm}$. After the SPS chamber was evacuated (4-6 Pa), the compacted powder was heated to $900-1000{ }^{\circ} \mathrm{C}$ at a rate of $100{ }^{\circ} \mathrm{C} \min ^{-1}$ and held for $5 \mathrm{~min}$. A constant pressure of $50 \mathrm{MPa}$ was applied on the compacted powder inside the graphite die along the $Z$-axis until the sintering process finished. The graphite die was cooled down naturally to room temperature, after which the sintered samples were taken out and cut into disks with a thickness of 1 $\mathrm{mm}$. Post-annealing was then carried out in two steps. First, the SPS samples were annealed in air at $700{ }^{\circ} \mathrm{C}$ for $4 \mathrm{~h}$, followed by another annealing in air at $1000{ }^{\circ} \mathrm{C}$ for $6 \mathrm{~h}$ to eliminate oxygen vacancies formed during the SPS process. Finally, the sintered disks were coated with silver paste on the upper and bottom surfaces and then baked at $600{ }^{\circ} \mathrm{C}$ for $10 \mathrm{~min}$ to form electrodes for electrical measurements.

The density of the samples was determined by the Archimedes method. A high-resolution X-ray diffractometer (Rigaku, 

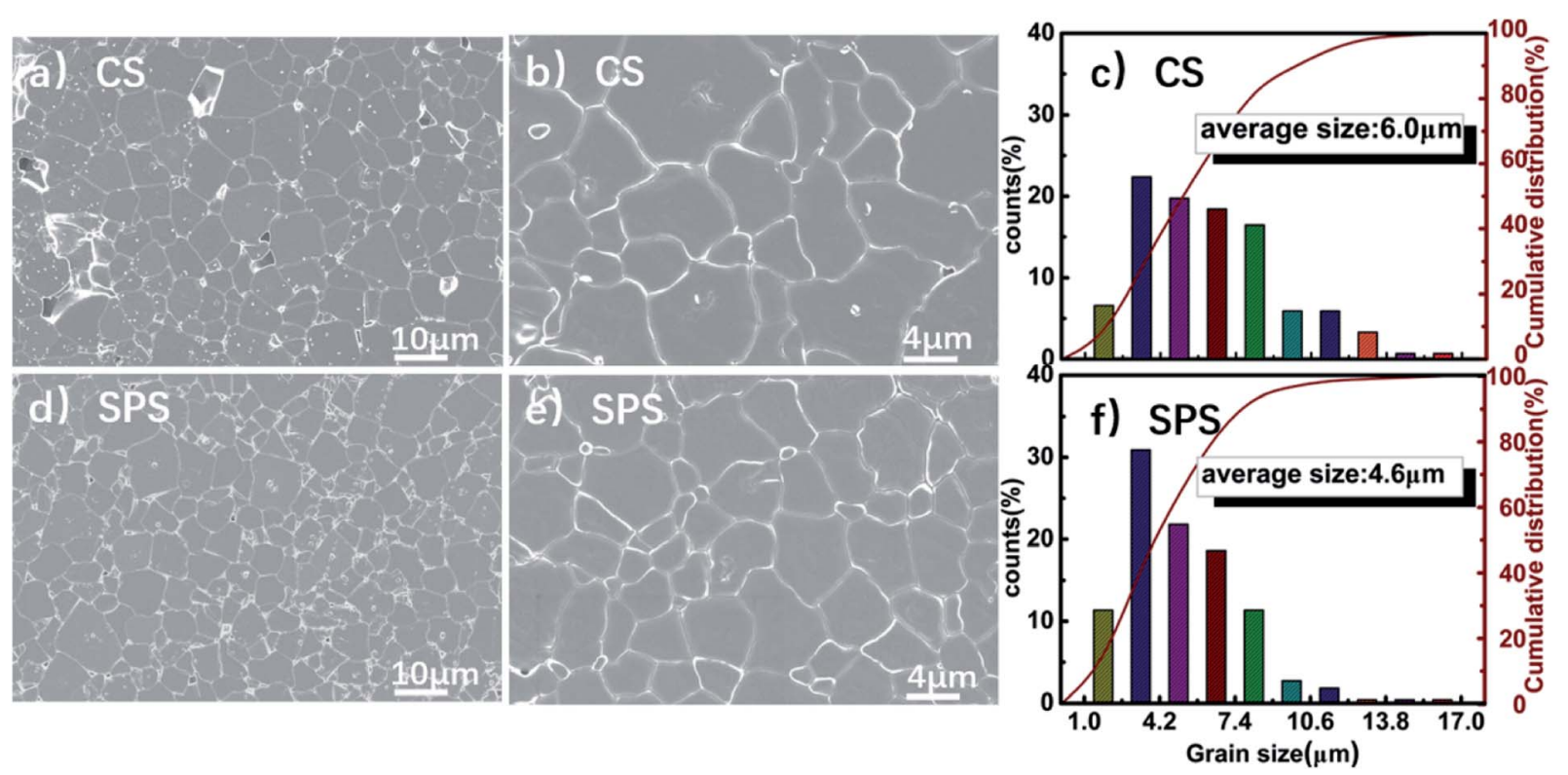

Fig. 2 SEM images of PZT-PMnN ceramics prepared by different sintering methods. (a) and (b) CSed ceramic after thermal etching at $1100{ }^{\circ} \mathrm{C}$; (c) grain size distribution of CSed ceramic; (d) and (e) SPSed ceramic after thermal etching at $1150{ }^{\circ} \mathrm{C}$; (f) grain size distribution of SPSed ceramic.

D/Max2500, Tokyo, Japan) is implemented to examine the crystal structure. Microstructures of sintered disks were examined by using a scanning electron microscopy (SEM, JSM6460LV, JEOL, Tokyo, Japan). The quasi-static piezoelectric coefficient $d_{33}$ of the poled samples was measured using a quasi-static $d_{33}$ meter (ZJ-3A, Institute of Acoustics, Beijing, China). Field-dependent parameters were measured by a ferroelectric tester (aixACCT TF Analyzer 1000, Germany), bipolar/ unipolar strain curves (S-E) and ferroelectric hysteresis $(P-E)$ loops were included. The dielectric properties were measured at a frequency of $1 \mathrm{kHz}$ using an impedance analyzer (TH2827, Changzhou Tonghui Electronic Co, China). Resistance $|Z|$ and phase angle $\theta$ were measured at room temperature, using an Agilent 4294A precision impedance analyzer.

\section{Results and discussions}

\subsection{Microstructure analysis}

Fig. 1 shows the X-ray diffraction patterns of PZT-PMnN ceramics prepared by using CS and SPS methods. It can be found that both ceramics present typical and pure perovskite structures, indicating that $\mathrm{Mn}$ and $\mathrm{Nb}$ are completely doped into the PZT, forming a good solid solution. $\mathrm{T}$ and $\mathrm{R}$ represent the rhombohedral and tetragonal phases, respectively. There is one peak (200) between $44^{\circ}$ and $46^{\circ}$ in the diffraction pattern of $\mathrm{R}$ phase and two peaks (002) and (200) between $44^{\circ}$ and $46^{\circ}$ in the diffraction pattern of $\mathrm{T}$ phase. ${ }^{19}$ The split peaks shown in
Fig. 1(d)-(f) confirm the presence of coexistence of R-T phase, ${ }^{22,23}$ which is consistent with the reported R-T morphotropic phase boundary in PZT-PMnN ceramics. ${ }^{24,25}$ The coexistence of $\mathrm{R}-\mathrm{T}$ phases provides more polarization directions and flexible domain rotation to the ceramic, which makes it easier to be polarized under an external electric field..$^{26,27}$ Comparing the XRD results of CSed and SPSed samples, it can be found that the sample prepared by SPS contains higher content of $\mathrm{T}$ phase, due to the value of $I(002) / I(200)$ of the T phase between $44^{\circ}$ and $46^{\circ}$ is $1: 2$, and the peak of the SPSed samples is closer to $1: 2$ here. ${ }^{28-30}$ In addition, as shown in Fig. $1(\mathrm{~g})$ and $(\mathrm{h})$, the R-phase characteristic peak of CSed ceramic more higher than that of SPSed ceramic, indicating the more R phase shows in CSed ceramic.

It can be seen from the SEM images (Fig. 2) that the SPSed ceramic possesses a denser microstructure than CSed ceramic. A lot of pores can be found in the CSed ceramic, as shown in Fig. 2(a), while there is no visible pore in SPSed ceramic, as shown in Fig. 2(d). Hence, the density of SPS-prepared ceramic is obviously larger than the CS-prepared ceramic (see Table 1). ${ }^{27}$ In addition, SPS-prepared ceramic has a suitable grain size distribution [see Fig. 2(f)], so that the grains can distribute more densely. The average grain size of the CSed ceramic is about 6.0 $\mu \mathrm{m}$, while the average grain size of SPSed ceramic is about 4.6 $\mu \mathrm{m}$. This is in agreement with the previous reports because the relatively short holding time during SPS will limit the grain growth. ${ }^{19}$ It is proposed that electrical properties depend on the

Table 1 The comparison of electrical properties of conventional sintering and spark-plasma-sintered PZT-PMnN ceramics sintered

\begin{tabular}{|c|c|c|c|c|c|c|c|c|c|c|}
\hline & $\rho\left(\mathrm{g} \mathrm{cm}^{-3}\right)$ & $d_{33}(\mathrm{pC} / \mathrm{N})$ & $d_{33}^{*}\left(\mathrm{pm} \mathrm{V}^{-1}\right)$ & $P_{\mathrm{r}}\left(\mu \mathrm{C} \mathrm{cm}{ }^{-2}\right)$ & $E_{\mathrm{C}}\left(\mathrm{kV} \mathrm{mm}^{-1}\right)$ & $k_{\mathrm{p}}$ & $Q_{\mathrm{m}}$ & $T_{\mathrm{C}}\left({ }^{\circ} \mathrm{C}\right)$ & $\varepsilon_{\mathrm{r}}(1 \mathrm{kHz})$ & $\tan \delta(1 \mathrm{kHz})$ \\
\hline CS & 7.71 & 323 & 318 & 11.9 & 0.92 & 0.553 & 182 & 359 & 451 & 0.0045 \\
\hline SPS & 7.89 & 412 & 553 & 18.8 & 1.49 & 0.585 & 583 & 354 & 827 & 0.0018 \\
\hline
\end{tabular}




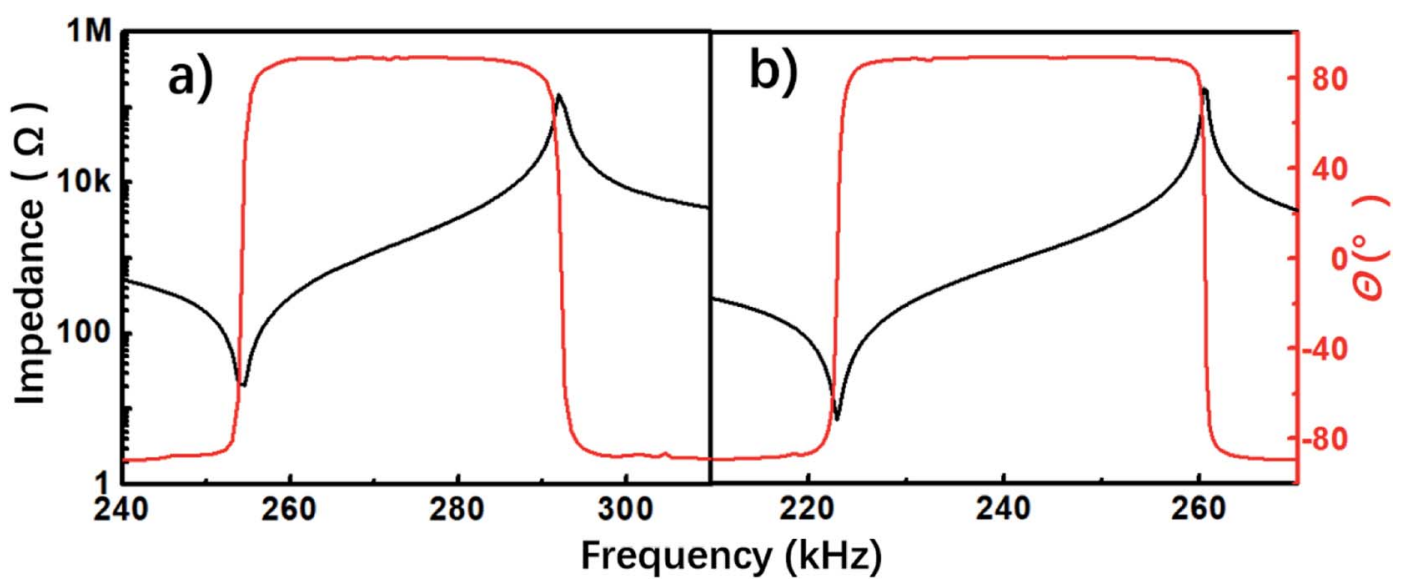

Fig. 3 Impedance $|Z|$ and phase angle $\theta$ spectra of PZT-PMnN ceramics prepared by different sintering methods measured as a function of the frequency of PZT-PMnN ceramics prepared by different sintering methods.

grain size. ${ }^{31}$ At an appropriate grain size, the electrical properties can be highly enhanced. As shown in Table 1, it can improve piezoelectric coefficient and strain of ceramics with decreased grain size and porosity. ${ }^{17}$ The piezoelectric effect of the piezoelectric ceramics is affected by the $90^{\circ}$ domain wall movement..$^{32}$ It is because that domain wall area will change as a function of grain size. A smaller domain can react strongly to the applied electric field as it can rotate more easily. ${ }^{31}$ The piezoelectric coefficients $d_{33}$ of CSed and SPSed samples were measured by using a quasi-static $d_{33}$ meter, as shown in Table 1. SPSed sample was found to possess an unexceptionally high $d_{33}$ when compared to the CSed sample. Therefore, it is conjectured that the smaller grain size achieved by using SPS method helps reduce the domain size, which potentially plays a significant role on the enhancement of piezoelectric performance.

\subsection{Measurement of electrical properties}

The impedance spectra and phase angle $\theta$ measured at $20^{\circ} \mathrm{C}$ are presented in Fig. 3 From the figure, the mechanical quality factor $\left(Q_{\mathrm{m}}\right)$ and the planar mode electromechanical coupling factor $\left(k_{\mathrm{p}}\right)$ can be evaluated, as shown in Table 1 . It can be seen that the $Q_{\mathrm{m}}$ of the SPSed ceramic (583) is three times higher than that of the CSed ceramic (182). Also, SPS method has also improved the $k_{\mathrm{p}}$ from 0.553 to 0.585 . This is related to the more $\mathrm{T}$ phase content in the phase structure of the ceramic and smaller grain size and porosity. ${ }^{17,28}$ This is consistent with the previous phase structure analysis (see Fig. 1 and phase structure analysis) and microstructure analysis (see Fig. 2 and microstructure analysis).

Fig. 4 shows $P-E$ hysteresis loops of PZT-PMnN prepared by different sintering methods. Typical ferroelectric loops were observed for both ceramics. Maximum polarization $\left(P_{\max }\right)$, residual polarization $\left(P_{\mathrm{r}}\right)$ and coercive field $\left(E_{\mathrm{C}}\right)$ were summarized in Table 1. It can be seen that the SPSed ceramic possesses a better ferroelectric performance $\left(P_{\max }=28.2 \mu \mathrm{C} \mathrm{cm}^{-2}\right.$ and $P_{\mathrm{r}}$ $\left.=18.8 \mu \mathrm{C} \mathrm{cm}^{-2}\right)$ than the CSed ceramic $\left(P_{\max }=20.1 \mu \mathrm{C} \mathrm{cm}^{-2}\right.$ and $P_{\mathrm{r}}=11.9 \mu \mathrm{C} \mathrm{cm}^{-2}$ ). In addition, the coercive field of SPSed ceramic is also higher than that of CSed ceramic. It is generally believed that the coercive field is related to the flexibility of domain and domain walls, and the coercive field of T-phase is generally larger than that of R-phase. ${ }^{29}$ SPS ceramic shows higher $E_{\mathrm{C}}\left(1.49 \mathrm{kV} \mathrm{mm}^{-1}\right)$ than CS ceramic $\left(0.92 \mathrm{kV} \mathrm{mm}^{-1}\right)$. This phenomenon is consistent with their XRD conclusions, and the XRD of SPS shows more obvious T-phase. It can be found that the content of the $\mathrm{T}$ phase in the coexisting phase affects the piezoelectric properties of the ceramic.

Fig. 5 shows temperature-dependent dielectric constant and loss of both SPSed and CSed PZT-PMnN ceramics. It can be seen from Fig. 5(a) that the Curie temperatures of the ceramics are quite similar. The Curie temperature of the SPSed ceramic is only $5{ }^{\circ} \mathrm{C}$ lower than that of the CSed ceramic. On the other hand, SPS can significantly increase the peak dielectric constant and the dielectric constant at room temperature. The dielectric constant at Curie temperature was increased from 21000 to 37000 and it was increased from 472 to 824 at room temperature. Besides, in Fig. 5(b), it can be seen that the SPS can largely reduce the dielectric loss of ceramic in various temperature ranges, and the loss was reduced from 0.0045 to 0.0018 at room temperature.

Fig. 6(a) shows bipolar strain curves of PZT-PMnN ceramics. It can be observed that the strain value of SPSed ceramic at room temperature is almost twice that of the CSed ceramic. In order to

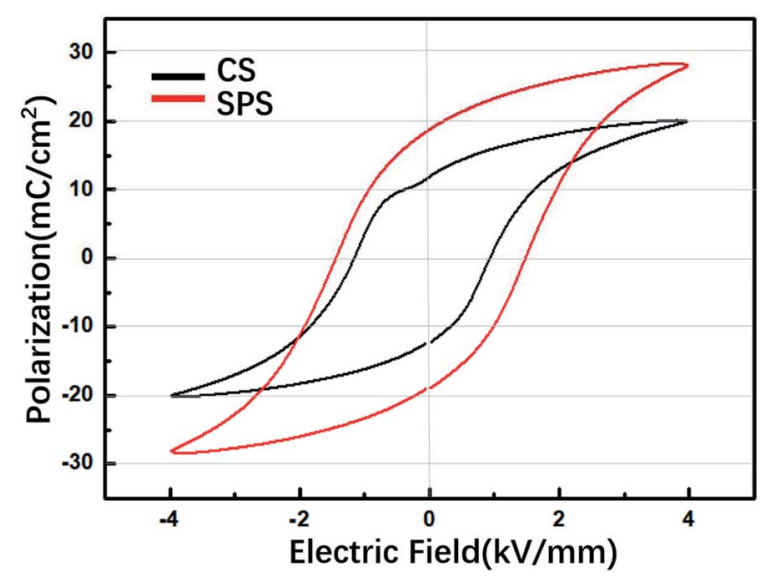

Fig. $4 P-E$ hysteresis loops of PZT-PMnN ceramics prepared by different sintering methods. 

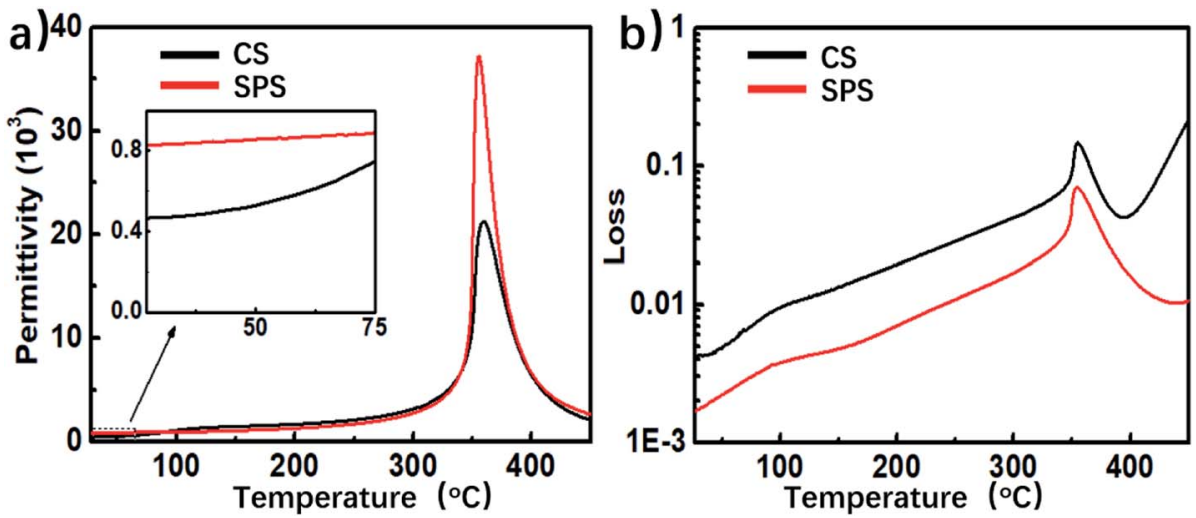

Fig. 5 Dielectric constants and losses of PZT-PMnN ceramics prepared by different sintering methods.
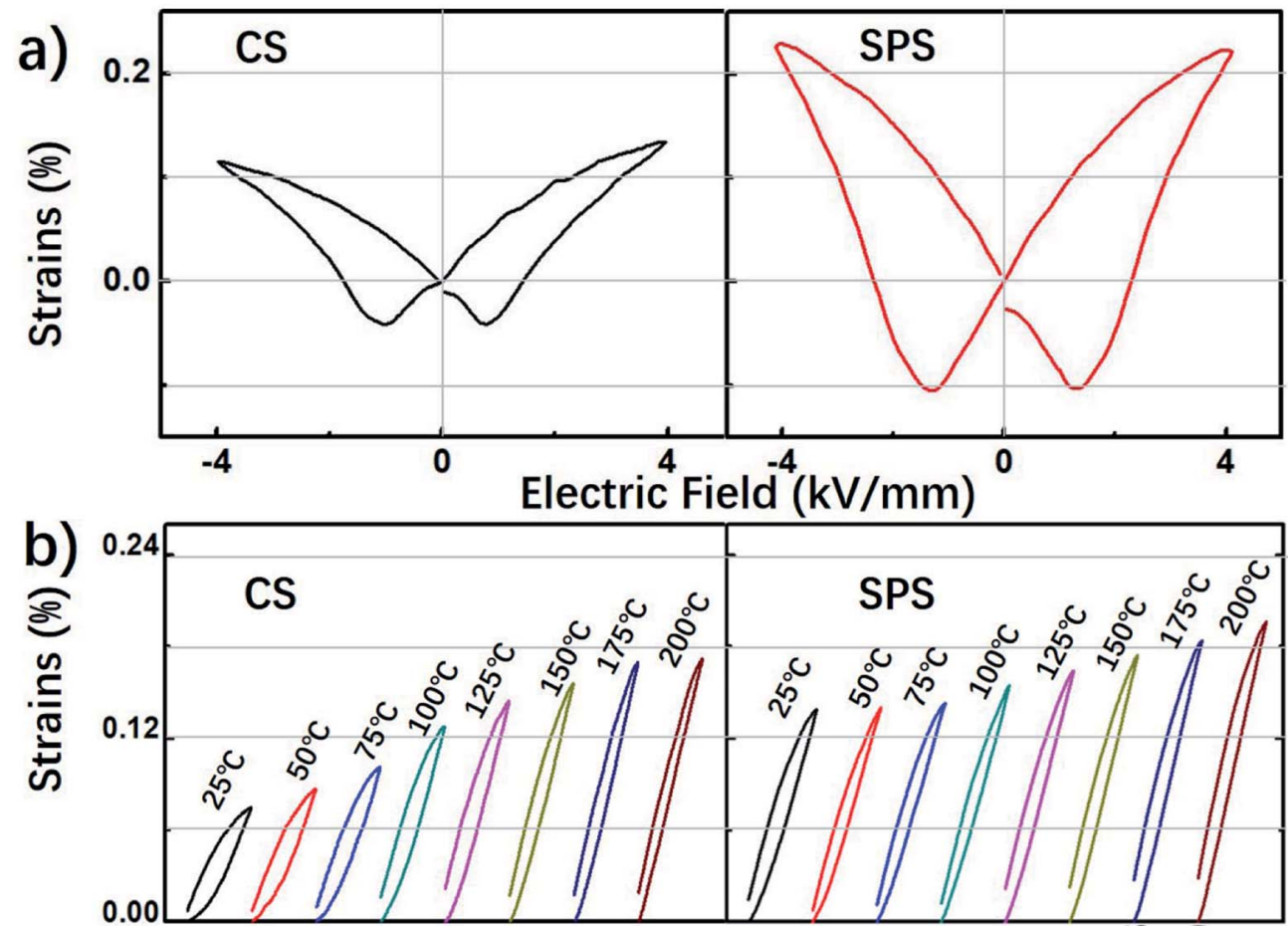

Electric Field $(2.5 \mathrm{kV} / \mathrm{mm})$

Fig. 6 Strain curves of PZT-PMnN ceramics prepared by different sintering methods. (a) Bipolar strain curves (b) unipolar strain curves as a function of temperature measured at an applied electric field of $2.5 \mathrm{kV} \mathrm{mm}^{-1}$.

verify the thermal stability of the strain performance, the unipolar strain was measured at various temperatures, ranging from $25{ }^{\circ} \mathrm{C}$ to $200{ }^{\circ} \mathrm{C}$. The unipolar strain can be normalized as $d_{33}^{*}$, which is also known as the converse piezoelectric coefficient. Similar to bipolar strain performance, a higher $d_{33}^{*}\left(553 \mathrm{pm} \mathrm{V}^{-1}\right)$ is observed in SPSed ceramic at room temperature, when compared to the CSed ceramic (318 $\mathrm{pm} \mathrm{V}^{-1}$ ). As shown in Fig. 6(b), when the temperature rises from $25{ }^{\circ} \mathrm{C}$, the unipolar strain of CSed ceramic greatly increases from $0.08 \%$ to $0.17 \%$ (variation of $112.5 \%$ ) while the SPSed ceramic only changes from $0.13 \%$ to $0.17 \%$ (variation of $33 \%$ ). The result suggests that SPSed ceramic possesses a thermally stable strain performance.
According to the above comparison, it is easy to find that the performance of PZT-PMnN ceramics can be optimized via SPS method. And SPSed ceramic has the higher strain, $d_{33}, \varepsilon_{\mathrm{r}}, P_{\mathrm{r}}, E_{\mathrm{C}}$, compactness, and lowest loss. The R-T phase structure with more $\mathrm{T}$ phase and denser and finer grain distribution are the main reasons for improving the ferroelectric properties of SPS ceramics. Hence, SPS not only reduced the sintering temperature by $300{ }^{\circ} \mathrm{C}$, but also greatly improved the ceramic performance. This work provides a powerful reference for future researchers, how to improve the $d_{33}$ and $Q_{\mathrm{m}}$ while the performance requirements getting bigger in practical applications. SPS may be a reliable means. 


\section{Conclusions}

A high-performance PZT-PMnN ceramic was prepared by SPS at 900-950 ${ }^{\circ} \mathrm{C}$. The SPS method can effectively reduce the sintering temperature and time, compared to the CS method. SPS was found to be able to enhance the density of the sintered ceramic, and meanwhile, decrease its average grain size. Besides, a remarked enhancement is observed in piezoelectric performances, including the piezoelectric coefficient and the converse piezoelectric coefficient. Furthermore, SPS also help improve the other properties, e.g. $k_{\mathrm{p}}, Q_{\mathrm{m}}$, and $\varepsilon_{\mathrm{r}}$. The unstable strain performance of CSed PZT-PMnN ceramics against rising temperature has been greatly mitigated in the SPSed ceramic as well. All of these improvements demonstrate that SPS is an exceptionally good processing method for PZT-PMnN system, which can provide upgraded materials for future applications.

\section{Conflicts of interest}

There are no conflicts to declare.

\section{Acknowledgements}

The authors acknowledge the financial supports from the National Natural Science Foundation of China (Grant No. 51602345), the State Key Laboratory of New Ceramics and Fine Processing, Tsinghua University (Grant No. KF201512), Fundamental Research Funds for the Central Universities (Grant No. 2016QJ01) and the Opening Fund of Acoustics Science and Technology Laboratory (Grant No. SSKF2016003).

\section{References}

1 X. Gao, X. Xin, J. Wu, Z. Chu and S. Dong, Appl. Phys. Lett., 2018, 112, 152902.

2 B. Narayan, J. S. Malhotra, R. Pandey, K. Yaddanapudi, P. Nukala, B. Dkhil, A. Senyshyn and R. Ranjan, Nat. Mater., 2018, 17, 427-431.

3 F. Li, S. Zhang, Z. Xu and L.-Q. Chen, Adv. Funct. Mater., 2017, 27, 1700310.

4 J. Li, F. Li, Z. Xu and S. Zhang, Adv. Mater., 2018, 1802155.

5 W. Jo, R. Dittmer, M. Acosta, J. Zang, C. Groh, E. Sapper, K. Wang and J. Rödel, J. Electroceram., 2012, 29, 71-93.

6 K. Song, Z. Li, H. Guo, Z. Xu and S. Fan, J. Appl. Phys., 2018, 123, 154107.

7 A. K. Yadav, A. Verma, S. Kumar, V. Srihari, A. K. Sinha, V. R. Reddy, S. W. Liu, S. Biring and S. Sen, J. Appl. Phys., 2018, 123, 124102.

8 F. Li, S. Zhang, T. Yang, Z. Xu, N. Zhang, G. Liu, J. Wang, J. Wang, Z. Cheng, Z.-G. Ye, J. Luo, T.-R. Shrout and L.-Q. Chen, Nat. Commun., 2016, 13807.

9 B. Jaffe, R. S. Roth and S. Marzullo, J. Appl. Phys., 1954, 25, 809-810.
10 B. Jaffe, R. S. Roth and S. Marzullo, J. Res. Natl. Bur. Stand., 1955, 55, 239-254.

11 M. Hammer, C. Monty, A. Endriss and M. J. Hoffmann, J. Am. Ceram. Soc., 1998, 81, 721-724.

12 S. Priya, H.-W. Kim and K. Uchino, J. Am. Ceram. Soc., 2004, 87, 1907-1911.

13 K. Wang, J.-F. Li and J.-J. Zhou, Appl. Phys. Express, 2011, 4, 061501.

14 M.-H. Zhang, K. Wang, Y.-J. Du, G. Dai, W. Sun, G. Li, D. Hu, H. C. Thong, C. Zhao, X.-Q. Xi, Z.-X. Yue and J.-F. Li, J. Am. Chem. Soc., 2017, 139, 3889-3895.

15 H. C. Thong, Q. Li, M.-H. Zhang, C. Zhao, K. X. Huang, J.-F. Li and K. Wang, J. Am. Ceram. Soc., 2018, 15488.

16 L.-Q. Cheng, K. Wang, Q. Yu and J.-F. Li, J. Mater. Chem. C, 2014, 2, 1519-1524.

17 C. Chen, R. Liang, Z. Zhou, W. Zhang and X. Dong, Ceram. Int., 2018, 44, 3563-3570.

18 T. Hungría, J. Galy and A. Castro, Adv. Eng. Mater., 2009, 11, 615-631.

19 B. Han, C. Zhao, Z. X. Zhu, X. Chen, Y. Han, D. Hu, M.-H. Zhang, H. C. Thong and K. Wang, ACS Appl. Mater. Interfaces, 2017, 9, 34078-34084.

20 Z.-Y. Shen, J.-F. Li, K. Wang, S. Xu, W. Jiang and Q. Deng, J. Am. Ceram. Soc., 2010, 93, 1378-1383.

21 K. Wang, J.-F. Li and N. Liu, Appl. Phys. Lett., 2008, 93, 092904.

22 T. Wu, Q. Sun, W. Ma and Z. Liu, J. Electroceram., 2013, 31, 28-34.

23 S. Shen, J. Chen, J. Jian, F. Luo, J. Mei and J. Cheng, J. Am. Ceram. Soc., 2018, 15804.

24 Y. Zhou, Q. Li, C. Xu, F. Zhuo, Q. Yan, Y. Zhang and X. Chu, J. Am. Ceram. Soc., 2018, 101, 3054-3064.

25 S. M. Gupta and D. Viehland, J. Appl. Phys., 1998, 83, 407414.

26 B. Hanrahan, Y. Espinal, C. Neville, R. Rudy, M. Rivas, A. Smith, M.-T. Kesim and S.-P. Alpay, J. Appl. Phys., 2018, 123, 124104.

27 F. Bian, S. Yan, C. Xu, Z. Liu, X. Chen, C. Mao, F. Cao, J. Bian, G. Wang and X. Dong, J. Eur. Ceram. Soc., 2018, 38, 31703176.

28 Z. Wu and R. E. Cohen, Phys. Rev. Lett., 2005, 95, 037601.

29 Z. Tan, J. Tian, Z. Fan, Z. Lu, D. Zheng, Y. Wang, D. Chen, M. Qin, M. Zeng, X. Lu, X. Gao and J.-M. Liu, Appl. Phys. Lett., 2018, 112, 152905.

30 A. Prasatkhetragarn and R. Yimnirun, Ceram. Int., 2013, 39, S91-S95.

31 N. Ma, B.-P. Zhang, W.-G. Yang and D. Guo, J. Eur. Ceram. Soc., 2012, 32, 1059-1066.

32 D. Damjanovic and M. Demartin, J. Phys. D: Appl. Phys., 1996, 29, 2057. 